\title{
Feasibility of guayule commodity chain in the Mediterranean region
}

\author{
Nisrine Sfeir, Didier Snoeck, Robert van Loo, \\ Thierry Chapuset, José Garcia Garcia, Frédéric Lançon
}

September 24, 2012 


\section{Why Guayule?}

$\checkmark$ Produces rubber with no evidence of human allergy;

$\checkmark$ Source of multiple products; (Resin, bagasse, oil, vegetable wax...);

$\checkmark$ Rapid growth producing;

$\checkmark$ Abundant biomass;

$\checkmark$ Disease resistant.

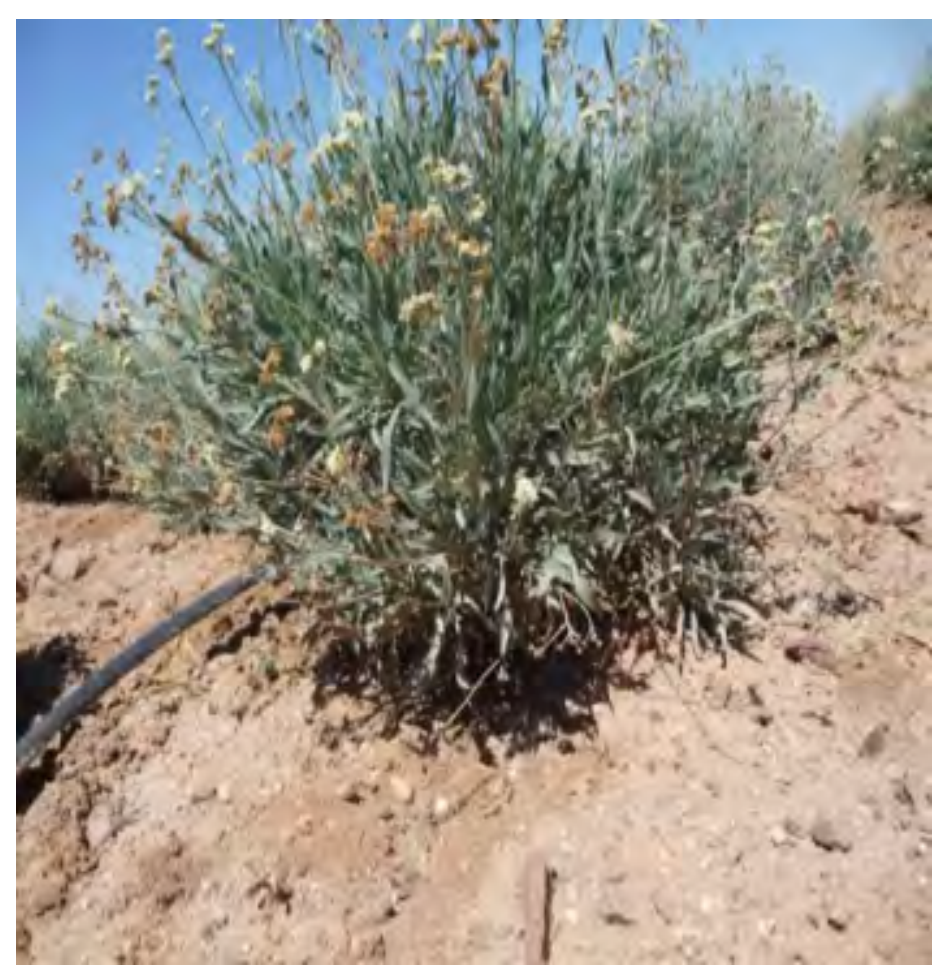




\section{Why Guayule in the Mediterranean?}

\section{Guayule : native to the Mexican desert}

$\checkmark$ Does not require much water (250-600 mm/year),

$\checkmark$ Adapted to semi-arid regions: most of Mediterranean areas.

Previous results showed that guayule is adapted to the ecology of the Mediterranean;

Production can be close to European industry;

Need for development projects and sustainable farming in the Mediterranean area (Climate Change). 


\section{Problem statements}

$>$ How far current research on agronomy and technology development of guayule can lead to a natural rubber commodity chain in the Mediterranean?

$>$ How far guayule cultivation can respond to local development in Mediterranean countries? 


\section{Guayule commodity chain}

A simplified model :

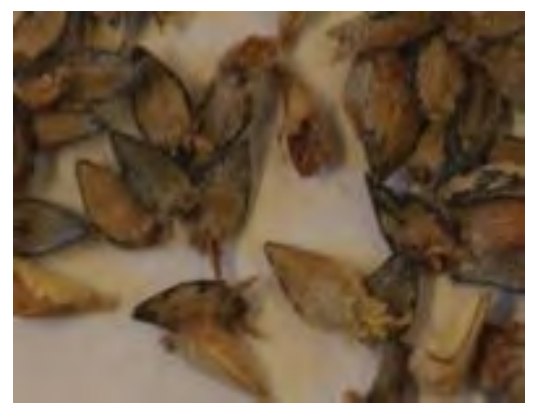

Guayule Seeds

\section{a) Farmer}

\section{b) Manufacturer}

Harvesting

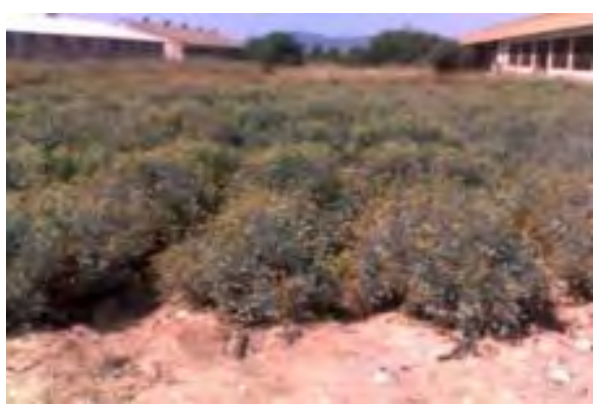

Biomass ready to be harvested

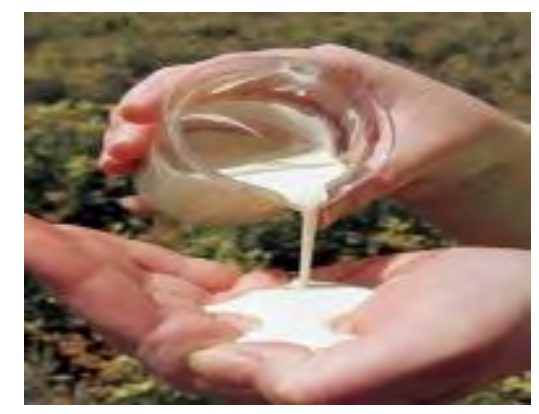

Rubber 


\section{Methodology}

$\rightarrow$ Technico-economic feasibility of a guayule commodity chain in southern Europe (micro-economic study).

$>$ Step 1: Study budget accounts of both agents of the commodity chain

* Farmer (Agronomy)

- Cultural practices and crop management to grow the bushes;

- Costs of inputs, labour.

* Manufacturer (Technology)

- Processing phases to extract the products out of the biomass;

- Costs of the plant: machinery, inputs, labour.

$>$ Step 2 : Adaptability of guayule chain in other southern Mediterranean countries (South Europe, North Africa, Middle East). 


\section{Agronomy: farming practices}

\section{Inputs:}

- Cultural practices and crop management used to compute the farmer's revenue (inputs + labour) were based on trials in Murcia and Montpellier. They include:

1. Nursery for production of plantlets,

2. Land preparation (ploughing, plastic mulching ...) and planting,

3. Land rental,

4. Drip irrigation, Fertilization, Pesticides (not used, for record only),

5. Labour for annual maintenance.

- Costs of inputs used to calculate each production activity were based on actual agricultural prices in Spain and France. 


\section{Agronomy: farming practices}

Outputs : The biomass is the only output at farmer's side

Guayule plantings in Montpellier

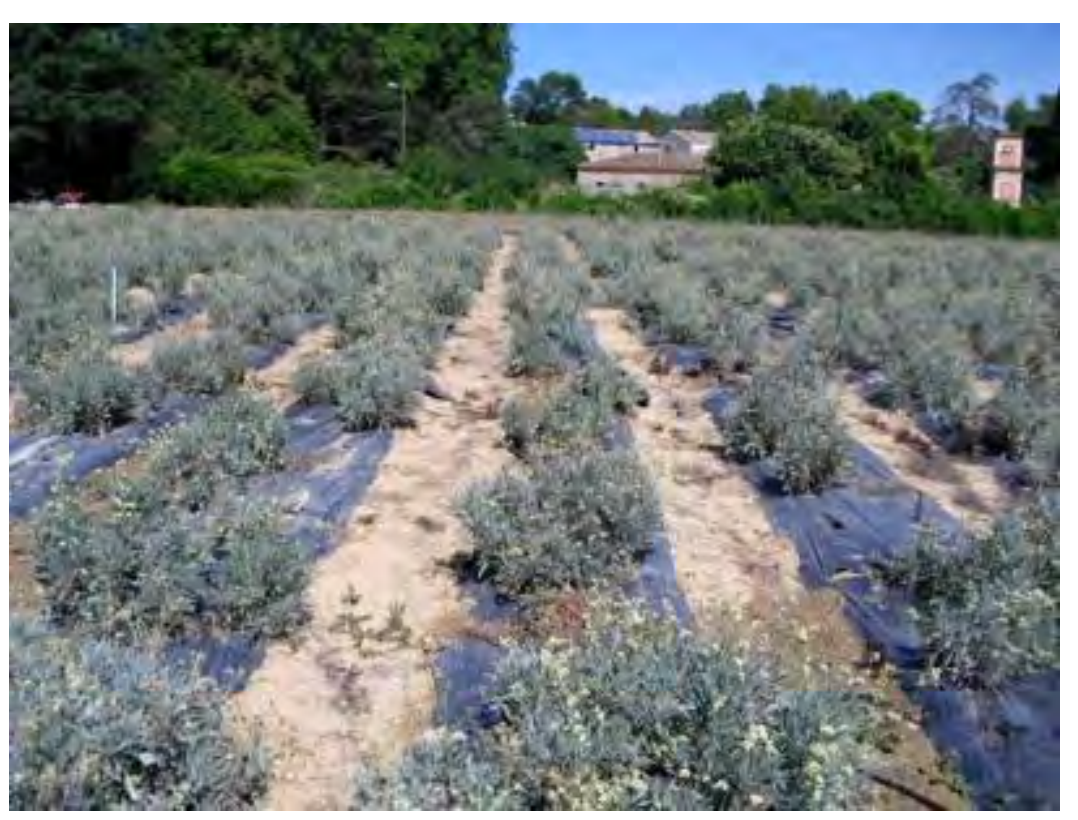

Guayule plantings in Spain

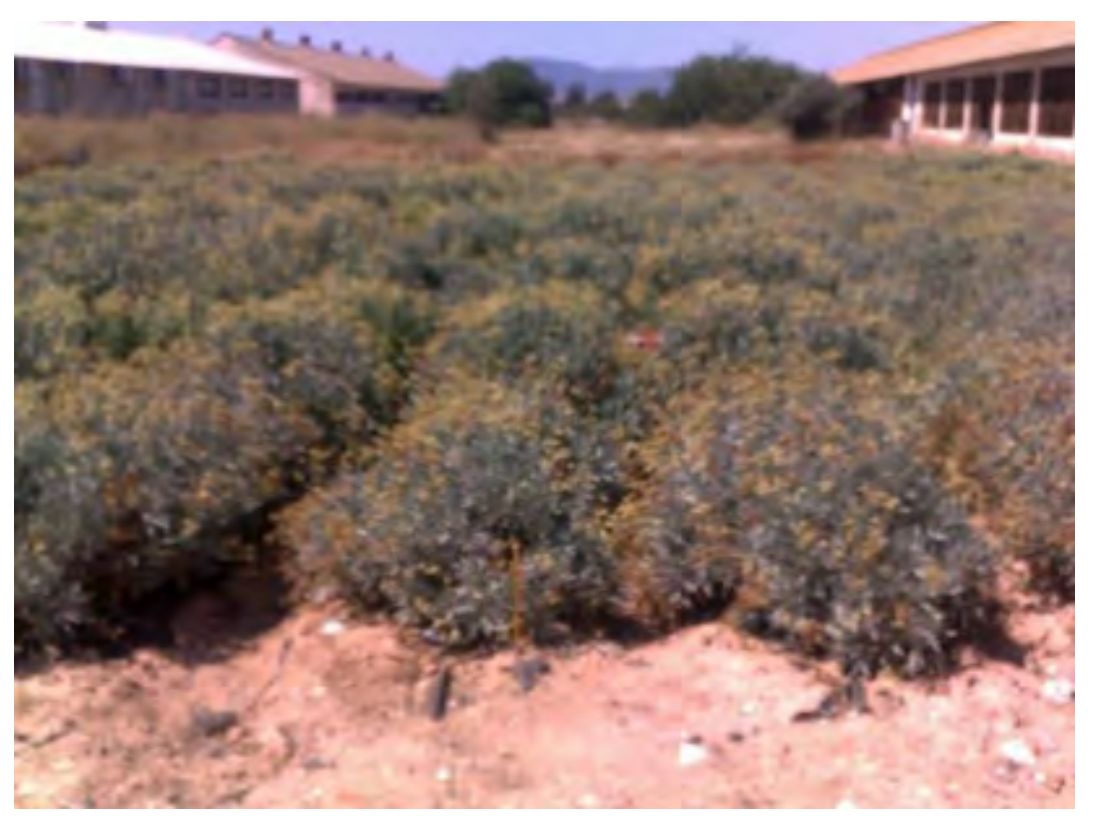




\section{Agronomy: Methodology}

\section{Uncertainty on some data:}

- Rubber yields,

- Plant behaviour to irrigation, fertilization,

- Harvest periodicity: annual or biennial.

Several hypothesis and simulations were tested

using a farm simulation

software (Olympe ${ }^{\mathrm{TM}}$ )

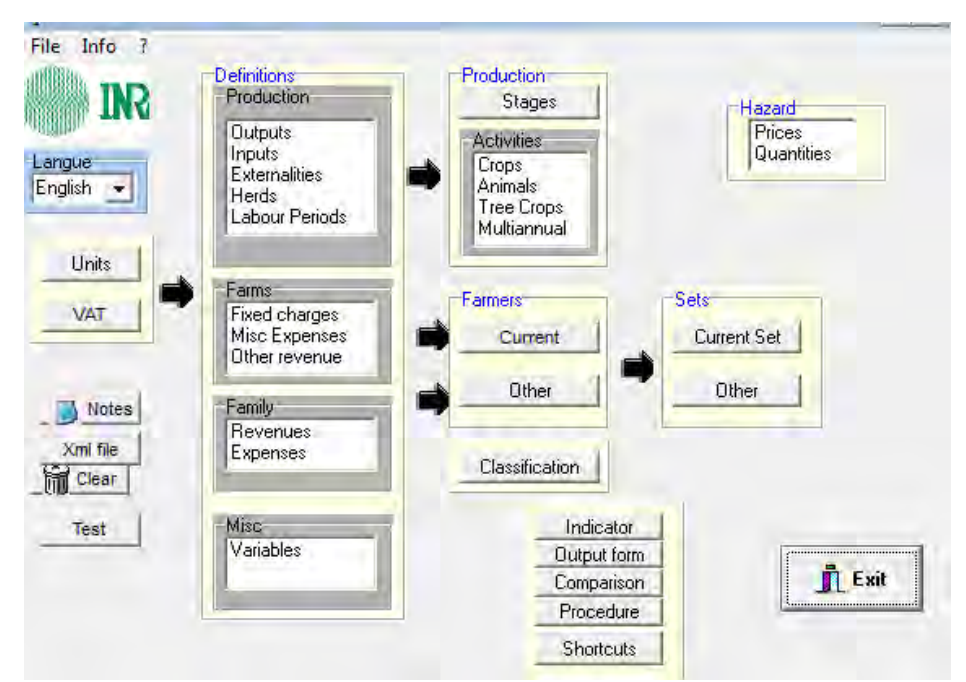




\section{Agronomy: Results}

\section{Example of results for two simulations}

\section{Inputs:}

Total costs (fixed and variable)

Price /ton / year

\begin{tabular}{|c|c|c|c|c|}
\hline & \multirow[b]{2}{*}{ Irrigation } & \multirow[b]{2}{*}{ Fertilisation } & \multicolumn{2}{|c|}{ Harvest periodicity } \\
\hline & & & Annual & Biennial \\
\hline Sim 1 & $\begin{array}{c}100 \% \\
\left(1600 \mathrm{~m}^{3} / \text { ha/year }\right)\end{array}$ & $\begin{array}{c}100 \% \\
(240 \mathrm{~kg} \mathrm{NPK} / \mathrm{ha} / \text { year })\end{array}$ & $€ 147$ & $\underline{€ 194}$ \\
\hline Sim 2 & $100 \%$ & $50 \%$ & $€ 142$ & $€ 188$ \\
\hline \multicolumn{5}{|c|}{ Outputs: } \\
\hline \multicolumn{3}{|c|}{$\begin{array}{c}\text { Biomass (tons of stem dry biomass / ha / year) } \\
\text { (at } € 300 / \text { ton) }\end{array}$} & $12 \mathrm{~T}$ & $9 \mathrm{~T}$ \\
\hline
\end{tabular}




\section{Technology: Methodology}

\section{Harvesting of fresh biomass}
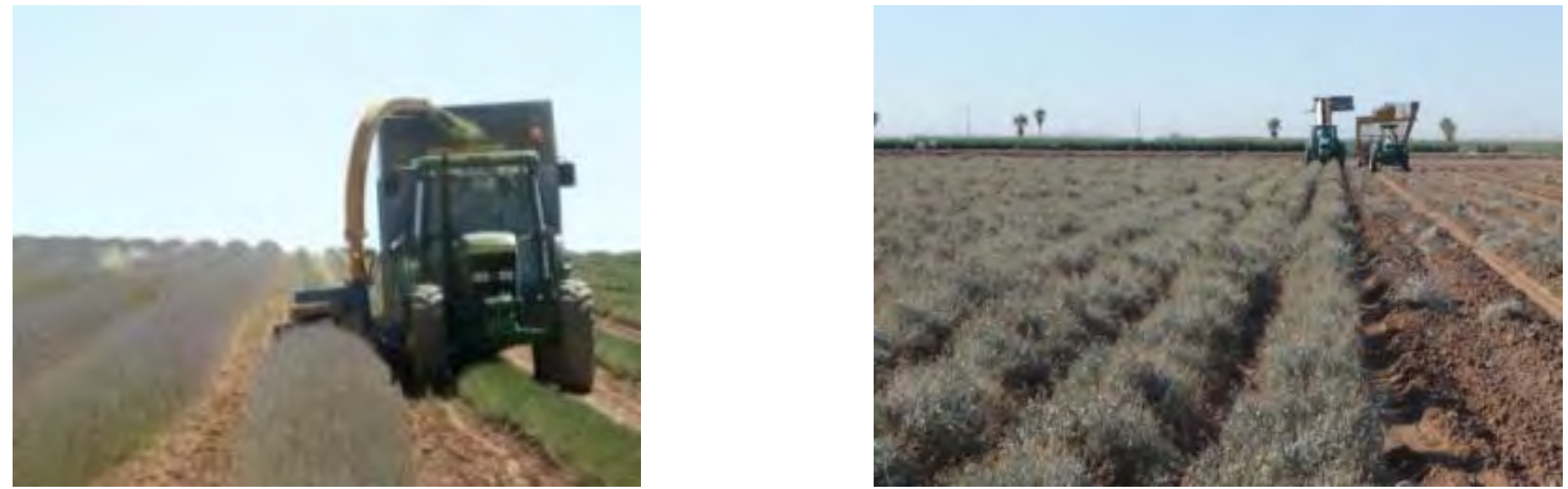

Harvesting tasks were given to the manufacturer because he needs to control the harvesting time to process only fresh material. 


\section{Processing: Methodology}

\section{Extraction and processing are not like Hevea}

\section{Guayule rubber is stuck inside the cells of the bark}

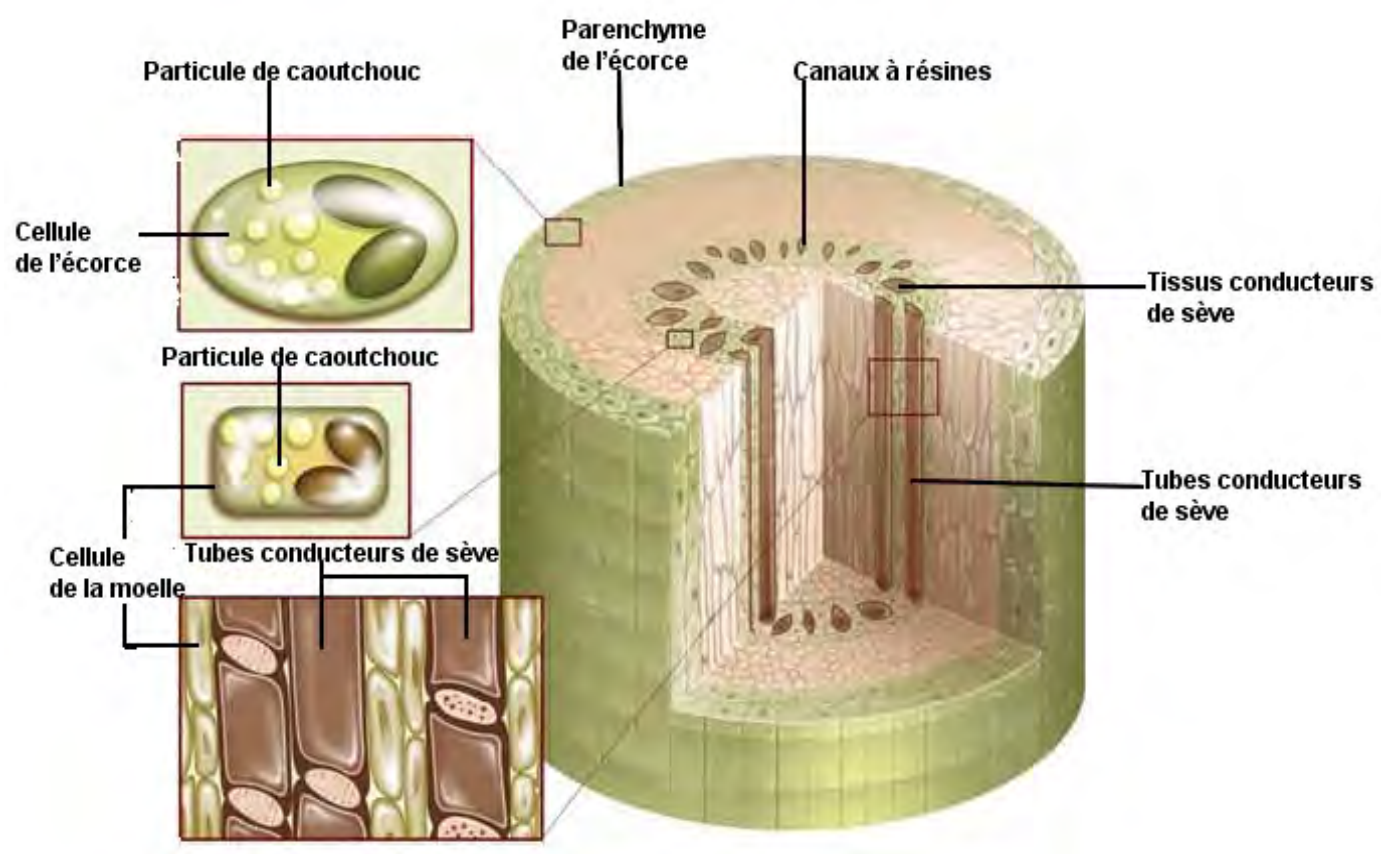

Hevea rubber is harvested by tapping the tree.

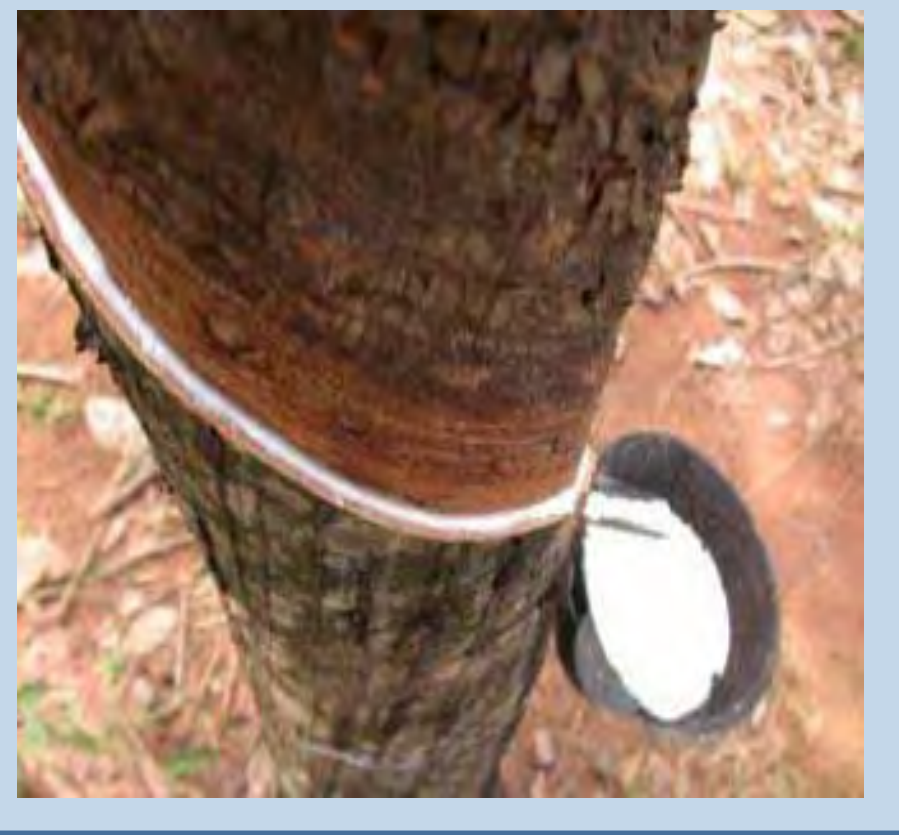

Guayule processing is more expensive than Hevea processing 


\section{Processing step 1: Latex extraction}

Ideal for medical and pharmaceutical products

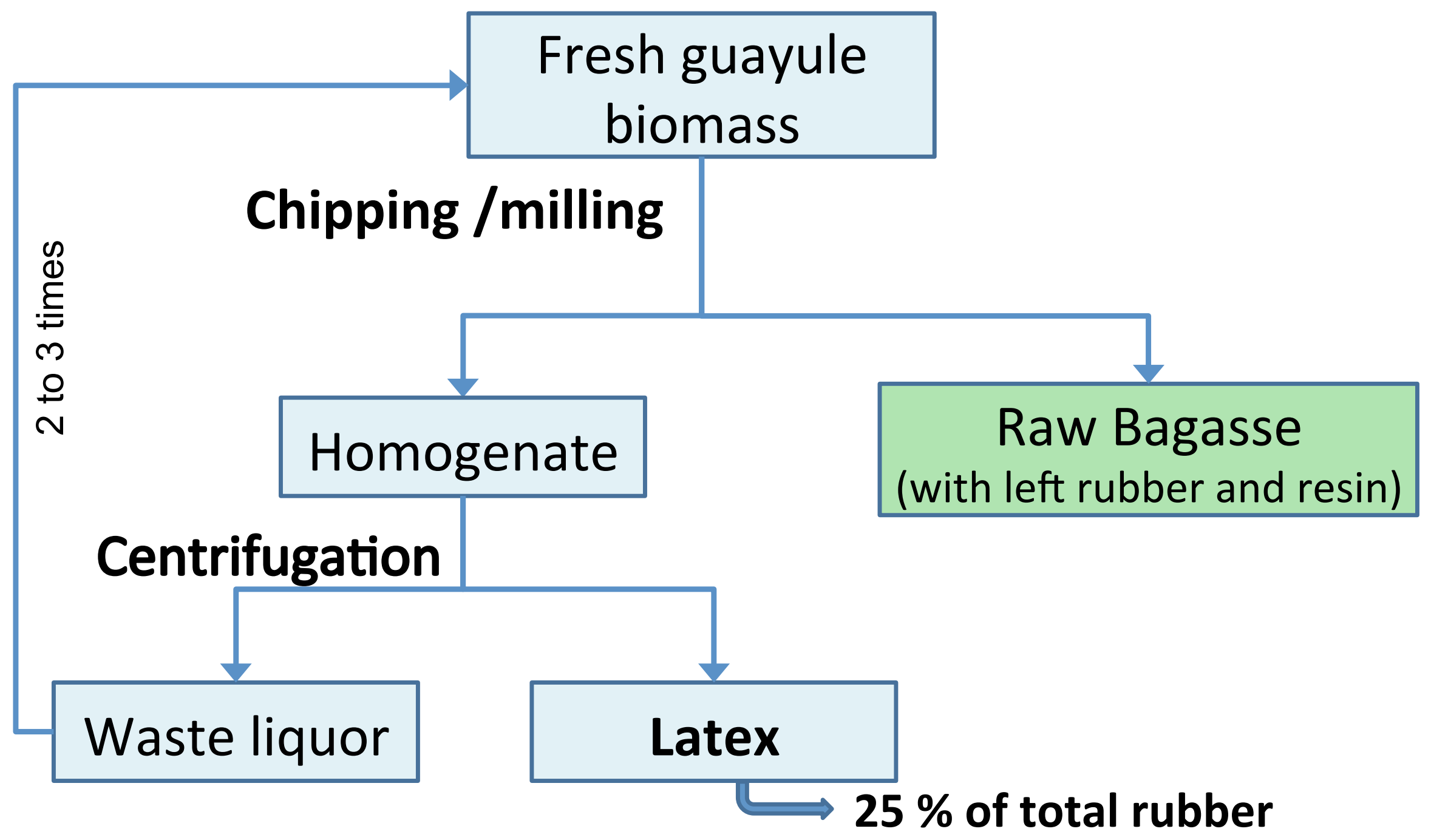




\section{Processing step 2: Solvent extraction}

Ideal for tire production

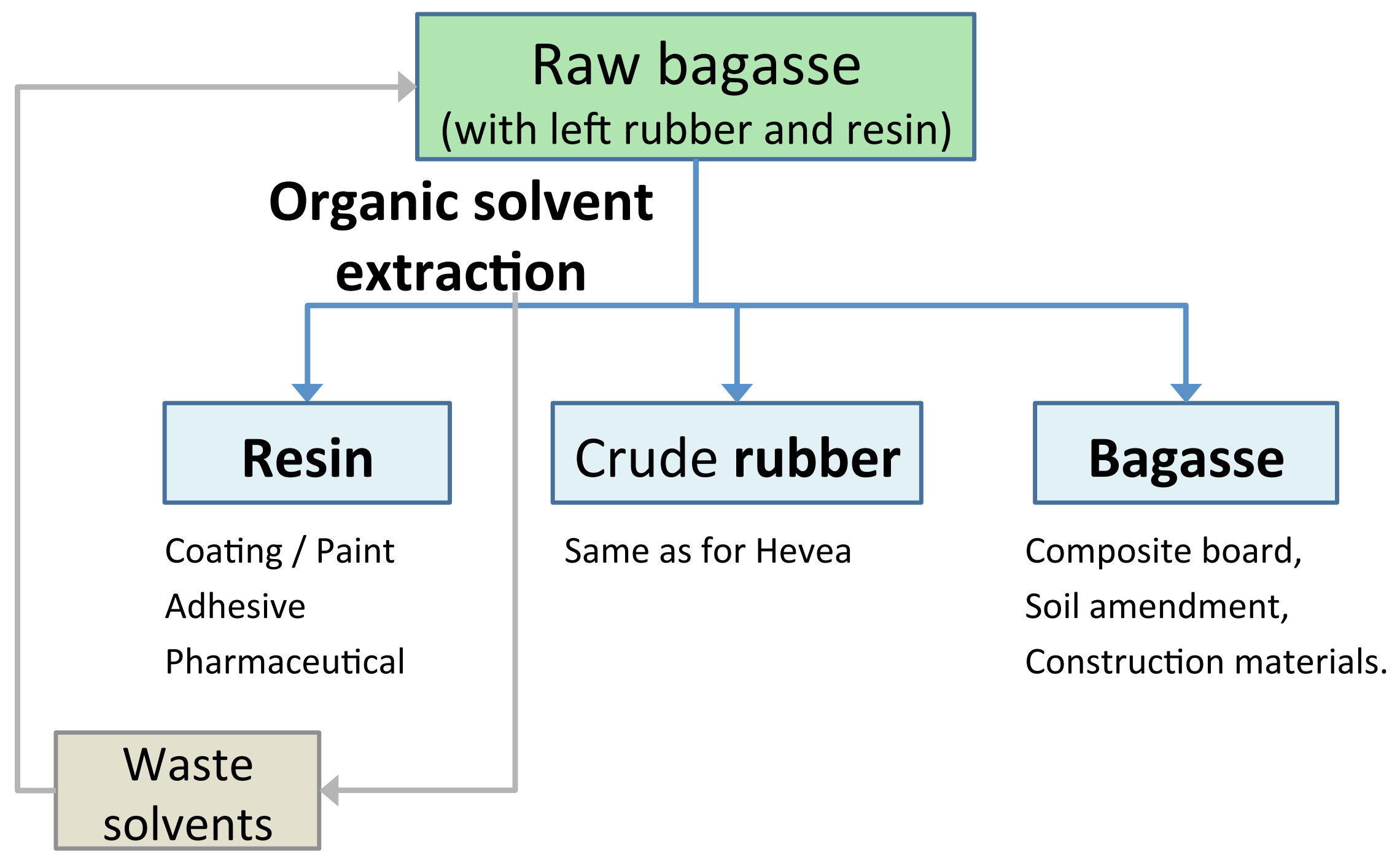




\section{Technology: Inputs}

> Factory size and processing were computed for a plant capacity of 17 tons of guayule stem dry biomass per day, during 4 months/yr.

$>$ Processing technology is based on data acquired from the Laboratory experience in Montpellier.

$>$ Costs include:

1. Buildings,

2. Fixed costs, Equipment, machinery,

3. Waste water cleaner,

4. Variable costs (harvest, transport, ...),

5. Labour, transportation, ...

\section{$>$ Uncertainty on data:}

Data were inspired from laboratory scale information. 


\section{Technology: Results}

\section{Costs of inputs and outputs}

\section{Extraction and processing:}

Dry biomass purchased (price / ton)

Processing: Latex extraction (step 1)

Solvent extraction (step 2)

\section{Outputs:}

Rubber $\rightarrow 9 \%$ of stem dry biomass

$25 \%$ as Latex (€6.00/ kg)

$65 \%$ by solvents ( $€ 3.60 / \mathrm{kg}$ )

Resin: $\rightarrow 9 \%$ of stem dry biomass $(€ 3.0 / \mathrm{kg}$ )

Bagasse: $\rightarrow 75 \%$ of stem dry biomass ( $€ 0.1 / \mathrm{kg}$ )

Total output:
Price / ton dry biomass $€ 300$

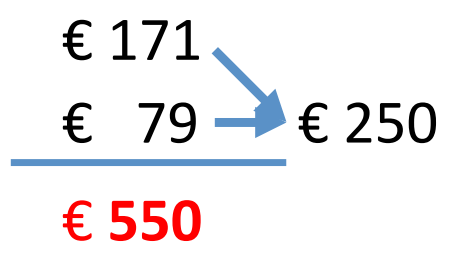

Price / ton dry biomass

$€ 135$

$€ 211$

$€ 270$

$€ 75$

$€ 691$ 


\section{Discussion}

\section{$>$ Agronomy}

Previous results showed that it is possible to grow guayule in Southern Europe. For a farm growing 1 ha during 10 years, we used the following figures:

- Stem dry biomass yields: 10 tons /ha /year (average for 10-year culture)

- Rubber content: $9 \%$ of dry rubber (i.e.: $900 \mathrm{~kg} / \mathrm{ha} /$ year)

- Planting density: 50,000 plants /ha

Production costs are estimated at: $€ 150$ to 200 /ton of stem dry biomass ( $€ 1,500$ to $€ 2,000 /$ ha /year).

Profit (if sold at $€ 300 /$ ton) can reach: $3,000-1,500=€ 1,500 /$ ha $/$ year. 


\section{Discussion}

\section{$>$ Processing}

Option 1: only Latex (centrifugation)

- With current technology, it is possible to extract $25 \%$ of the total rubber as latex.

$>$ The valorisation of sole guayule latex would be possible only through a niche market with very high added value.

Option 2: only crude rubber + resin (solvent extraction)

- With current technology, it is possible to extract $90 \%$ of rubber $+95 \%$ of the resin.

$\checkmark$ (Prices recorded in 2011).

Option 3: Latex as step 1, followed by crude rubber + resin as step 2.

- It is possible to extract $25 \%$ of latex $+65 \%$ of crude rubber $+95 \%$ of resin.

Threshold selling price $(€ / \mathrm{kg})$ to reach profitability

\begin{tabular}{|c|c|c|c|}
\hline Option & Latex & Crude rubber & Resin \\
\hline 1. Latex only & 25 & & \\
\hline 2. Solvent only & & 4 & 3 \\
\hline 3. Latex, then solvent & 5 & 3 & 3 \\
\hline
\end{tabular}




\section{Discussion}

$>$ Based on our results, we can consider that, even though the technology is not yet optimum, we were able to obtain positive financial account for both the farmer and the manufacturer.

$>$ The accounts of the processing plant were based on extrapolation of data from a pilot plant.

$\rightarrow$ Improvement is possible, and research should go forward to increase the capacity to extract more rubber and promote the by-products. 


\section{Discussion}

\section{The case of countries south of the Mediterranean sea}

\section{Lands}

- Land rental value is half the price of European (in semiarid region).

\section{Labour}

- Labour costs are lower by $20 \%$ as compared to European costs.

$\rightarrow$ Mechanical activities can be replaced by manual.

\section{Water availability}

- In South Mediterranean countries, water is a limited factor, but there is sufficient groundwater which can be used for irrigation.

$\checkmark$ Low input costs in the south can increase farmers' revenue. However, land availability is still to be questioned and studied.

$\checkmark$ Guayule, being a semi-desertic shrub, could be an opportunity for those countries. And more, it can be combined with other crops requiring little water

$\rightarrow$ a way to preserve water. 


\section{Conclusion}

$\checkmark$ Based on current knowledge, if rubber is used as the sole source of income, guayule will not be profitable in the Mediterranean. To make the culture profitable, the resin must be added, and optionally the bagasse.

$\checkmark$ Southern Mediterranean region can be a field to enlarge the development of guayule, which can be a new agricultural sector in the area.

$>$ For example, in Morocco, more than $50 \%$ of the none-desert land (Sahara) are unused semi-arid lands.

$\checkmark$ More efforts should still be given to the development of this plant to:

$>$ Guarantee high yields: genetic material, irrigation and fertilization.

$>$ Increase the capacity to extract more rubber and promote the by-products. 


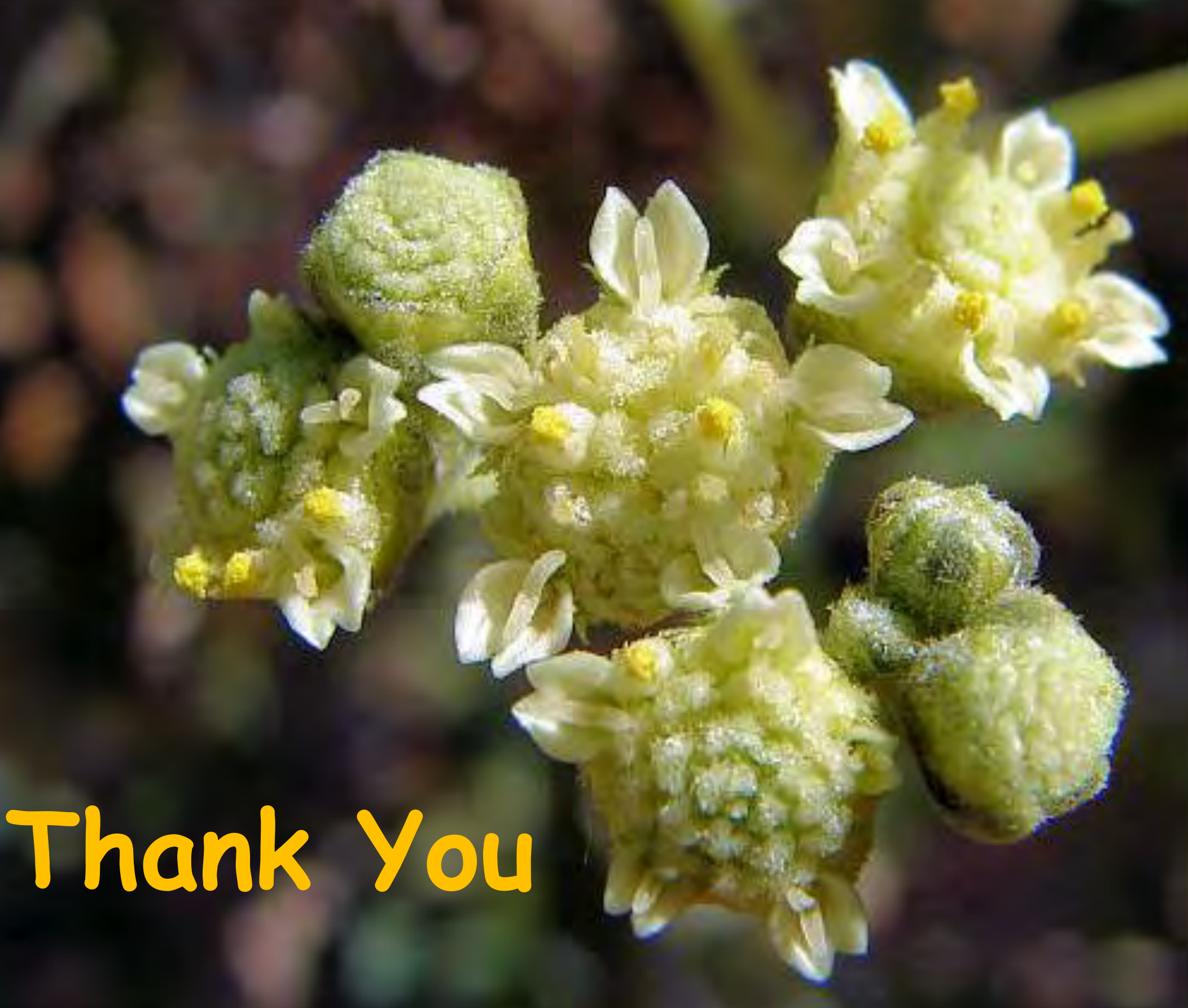

